\title{
On Winter Wheat Irrigation Scheme Optimization in the Wohushan Basin
}

\author{
Ke Kong ${ }^{1, a}$, Kun Wang ${ }^{1, b}$ and Yuan Xiu ${ }^{1, c}$ \\ ${ }^{1}$ University of Jinan, Jinan, Shandong Province, China \\ aemail:koker@sohu.com, bemail:1015157780@qq.coml, `email:xiuyuan1990@sina.com
}

\begin{abstract}
Keywords: Wohushan basin; winter wheat; irrigation quota; optimization
Abstract. In order to reduce the water consumption of agriculture to relieve the contradiction between supply and demand in the Wohushan basin, this paper get the effective rainfall in typical years by analyzing the series of rainfall of many years in this basin, and then calculated the water requirement for growth of winter wheat. According to the principle of water balance, the amount of irrigation water needed in the whole growth period was calculated, therefore the optimal irrigation scheme was obtained, which was $11 \%$ lower than that of general irrigation quota. This work is helpful for saving regional water resources, and has a positive significance to promote the development of regional social economy.
\end{abstract}

\section{Introduction}

Current agricultural water consumption of china accounts for the total amount of $60-70 \%$, therefore cutting down the agricultural water to ease the problem of water resources has an important significance. The optimization of irrigation water amount can decrease the use of water resources and increase its utilization efficiency [1,2]. In addition, this method can also achieve the purpose of saving water and increasing the runoff of the river basin.

The Wohushan basin is located in Licheng District of Ji'nan, covering the town of Zhonggong, Liubu and Xiying, and finally goes into the Yufu river. The economy of this basin was dominated by agriculture, the main economic crops and grain crops are respectively vegetables and winter wheat. In the past ten years, the industry and tourism had a great development, and the population increased rapidly, the contradiction between supply and demand of water resources also intensified. Therefore, this study aimed to optimize the irrigation quota of winter wheat in order to save water resources to support the sustainable development of the social economy.

\section{Hydrology Situation of the Basin}

The Wohushan basin belongs to warm temperate continental monsoon climate zone, the average temperature of many years is $13.4^{\circ} \mathrm{C}$, the average annual precipitation(from 1984 to 2013 ) is $703.2 \mathrm{~mm}$, the seasonal change of rainfall is obvious, highly concentrated rainfall occurs in the flood season(from June to September), the precipitation is $75 \%$ of the annual precipitation, especially in July and August, its precipitation is $51.2 \%$ of the annual precipitation, during the period, heavy rains frequently, raining heavily, heavy rainfall, it is easy to form heavy flood.

The main meteorological stations of the Wohushan basin include Wohushan, Liubu, Xiying, Zaolin and Wopu. According to the Tyson deformation method, averaging the data of the five meteorological stations which from 1984 to 2013 . We can get the data in Table 1.

Through calculating, we can get coefficient of variation, $\mathrm{Cv}=0.25$. According to the actual station of the Wohushan basin, we get deviation coefficient, $\mathrm{Cs}=2 \mathrm{Cv}=0.50$, we can get frequency curve of annual precipitation in the Wohushan basin. According to the frequency curve, we can get the annual precipitation which under $50 \%$ reliability is $688.6 \mathrm{~mm}$, we choose 2009 which of the annual precipitation is the nearest to it as normal year. Many factors influce the yeids of winter wheat [3].The rainfall related to irrigation is effective rainfall, and it is the precipitation which infiltrates into soil. 
We use $\alpha$ to represent the coefficient of infiltration of rainfall, single precipitation, the strength of rainfall, rainfall duration, ground covers, soil property and landform of the area can influence it, antecedent soil moisture and plans for the wet layer depth are also the important influence factors. In the same area, last precipitation characteristic and the current crop evaporation and transpiration intensity influence $\alpha$ directly. The value of $\alpha$ can be estimated by Eq.1:

$$
\alpha=\left\{\begin{array}{lc}
0 & P<5 \mathrm{~mm} \\
0.9 & 5 \mathrm{~mm}<P<50 \mathrm{~mm} . \\
0.7 & 50 \mathrm{~mm}<P
\end{array}\right.
$$

In Eq.1 $P$ denotes precipitation. Through calculating, the effective rainfall is $575.9 \mathrm{~mm}, 82.1 \%$ of rainfall of the whole year. The effective rainfall of winter wheat during the growth period (whole October, November, December, January, February, March, April, May and before June 10th) is $154 \mathrm{~mm}$.

Table1 Row frequency results table of 30 years of Wohushan basin

\begin{tabular}{cccccccc}
\hline Year & $\begin{array}{c}\text { Precipitation } \\
{[\mathrm{mm}]}\end{array}$ & No & Frequency & Year & $\begin{array}{c}\text { Precipitation } \\
{[\mathrm{mm}]}\end{array}$ & No & Frequency \\
\hline 2004 & 1060 & 1 & 0.032 & 2009 & 701.8 & 16 & 0.516 \\
2003 & 985.6 & 2 & 0.065 & 1984 & 700.6 & 17 & 0.548 \\
2005 & 965.4 & 3 & 0.097 & 2011 & 667.1 & 18 & 0.581 \\
1987 & 909.8 & 4 & 0.129 & 2006 & 652.5 & 19 & 0.613 \\
1994 & 872.2 & 5 & 0.161 & 1997 & 618.1 & 20 & 0.645 \\
1993 & 834.2 & 6 & 0.194 & 1985 & 606.6 & 21 & 0.677 \\
1996 & 834 & 7 & 0.226 & 2001 & 599.3 & 22 & 0.710 \\
2010 & 820.9 & 8 & 0.258 & 1995 & 596.8 & 23 & 0.742 \\
2007 & 797.1 & 9 & 0.290 & 1999 & 574.8 & 24 & 0.774 \\
1990 & 779.7 & 10 & 0.323 & 2012 & 569.1 & 25 & 0.806 \\
1991 & 776 & 11 & 0.355 & 1988 & 550.5 & 26 & 0.839 \\
1998 & 772.5 & 12 & 0.387 & 1992 & 541.1 & 27 & 0.871 \\
2013 & 736 & 13 & 0.419 & 2002 & 456.6 & 28 & 0.903 \\
2000 & 721.2 & 14 & 0.452 & 1989 & 365 & 29 & 0.935 \\
2008 & 705.1 & 15 & 0.484 & 1986 & 327 & 30 & 0.968 \\
\hline
\end{tabular}

\section{Optimization of Irrigation Schemes}

According to the current irrigation quota (DB37/T1640-2010) of Shandong province, in 50\% of the guaranteed rate of winter wheat in Wohushan basin during the whole growth period, the gross irrigation quota was $288 \mathrm{~m}^{3} / \mathrm{mu}$, not including the amount of irrigation before sowing. Obviously the current irrigation quota is relatively extensive, and it is insufficient to consider the stochastic nature of the crop water demand and precipitation. Therefore, the current irrigation scheme should be optimized according to the precipitation distribution of the typical year. Under the premise of satisfying the water requirement of every growing stage of the crop, the irrigation water quantity can be reduced as much as possible to achieve the purpose of water saving.

(1) Crop water demand forecast

Crop water requirement is the total amount of plant transpiration and evaporation during the whole growing period. The main factors include meteorological conditions, crop species, soil properties and 
agricultural technology level. Referring to the research on the equivalent line map of China's main crop water requirement and the experimental results of Shandong Water Conservancy Science Research Institute [4,5], and combined with the actual situation of irrigation of the Wohushan basin, determine the crop water requirement in the whole winter wheat growing period is $300 \mathrm{~m}^{3} / \mathrm{mu}$.

(2) Principle of determination of irrigation quota in growth period

For dry crops, the water content of planned moist layer in soil is the basis for the determination of irrigation water quantity. According to the principle of water balance, in any period ( $t$ ) of the whole growth period, the change of water content in planned moist layer $(Z)$ can be expressed by the water balance Eq.2:

$$
W_{t}-W_{0}=W_{T}+P_{0}+K+M-E T
$$

where $W_{0}$ denotes initial water content of planned moist layer in period $\mathrm{t}\left[\mathrm{m}^{3} / \mathrm{mu}\right] ; W t$ is water content of planned moist layer in soil at the time of $\mathrm{t}\left[\mathrm{m}^{3} / \mathrm{mu}\right] ; W_{T}$ is variable water quantity caused by the change of planned moist layer depth $\left[\mathrm{m}^{3} / \mathrm{mu}\right] ; P_{0}$ is effective rainfall that is kept in planned moist layer of soil $[\mathrm{mm}] ; K$ is groundwater recharge during the period of $\mathrm{t}\left[\mathrm{m}^{3} / \mathrm{mu}\right] ; M$ is irrigation water during the period of $\mathrm{t}\left[\mathrm{m}^{3} / \mathrm{mu}\right]$;ET is crop water requirement during the period of $\left.\mathrm{t}^{3} / \mathrm{mu}\right]$.

In order to ensure the normal growth of crops, the water storage of planned moist layer in soil has a value range in the growth stage. Rainfall is a random and discontinuous recharge source. If there is little precipitation, crops need for artificial irrigation.

(3) Determination of each term in the water balance equation

$W_{0}$ : The winter wheat initial water content of soil planned moist layer is $53 \mathrm{~m}^{3} / \mathrm{mu}$ in Wohushan basin by statistical calculation.

$W_{T}$ : The depth of soil planned moist layer changes with the change of growth stages. The calculation formula is given as Eq.3:

$$
W_{T}=6.67\left(Z_{2}-Z_{1}\right) \theta_{a} .
$$

where $\left(Z_{2}-Z_{1}\right)$ denotes the increase of the depth of soil planned moist layer; $\theta_{a}$ is average water content of the increased depth, in order to the volume percentage that account for the soil volume.

$K$ (groundwater recharge): Groundwater recharge refers to the absorbed and utilized water which rise to the root system of crops by capillary action. Basin of Wohushan is located in the southern mountainous area where the groundwater depth in wet season is $7 \mathrm{~m}$. So the groundwater recharge can be ignored here.

\section{Results of Optimizing Irrigation Scheme}

(1)The irrigation quota in the whole growth period of winter wheat

According to the above data and formula (1) for daily calculation, need to consider the winter wheat optimization irrigation quota with the changing of precipitation in the whole growth period, as shown in Table 2.

The initial soil water content $53 \mathrm{~m}^{3} / \mathrm{mu}$, the actual irrigation quota in the whole growth period of winter wheat should remove this part of water, so the irrigation quota of winter wheat in Wohushan basin is $144 \mathrm{~m}^{3} / \mathrm{mu}$.

(2)The determination of irrigation quota before sowing

To water winter wheat before sowing time to ensure that the crops in the seed germination and emergence, the amount of irrigation can be calculated by Eq.4

$$
M_{1}=6.67 Z\left(\theta_{\max }-\theta_{0}\right)
$$


$Z$ indicates that the soil depth of planning wetting zone; $\theta \max$ indicates the field water-holding rate; $\theta_{0}$ indicates that the soil water content of the depth of $Z$.

The value of $M_{1}$ is $27 \mathrm{~m}^{3} / \mathrm{mu}$ when the $\theta_{0}$ account for $\theta \max$ of $60 \%$.

(3)The total irrigation quota

The sum of irrigation quota in the whole growth period of crops and the quota before sowing is the total irrigation quota, the value $M$ is $170 \mathrm{~m}^{3} / \mathrm{mu}$, which is net irrigation quota, the utilization efficiency of canal system should also be considered in practice. The utilization coefficient of agricultural water of Wohushan basin is 0.58 , so the total irrigation quota is $293 \mathrm{~m}^{3} / \mathrm{mu}$, the total irrigation quota in the whole growth period is $248 \mathrm{~m}^{3} / \mathrm{mu}$, it is reduced by $40 \mathrm{~m}^{3} / \mathrm{mu}$ than the current irrigation quota of Shandong province, and irrigation times and irrigation time remained unchanged.

Table 2 The results of irrigation quota for winter wheat

\begin{tabular}{|c|c|c|c|c|c|c|c|}
\hline & Seeding & Overwinter & Regreen & Joint & Heading & Grout & Total \\
\hline $\begin{array}{l}\text { Start and } \\
\text { end date } \\
\text { Water }\end{array}$ & $10.1-11.10$ & $11.11-2.25$ & $2.26-4.10$ & $4.11-5.10$ & $5.10-5.31$ & $6.1-6.10$ & \\
\hline $\begin{array}{c}\text { Requirment } \\
{\left[\mathrm{m}^{3} / \mathrm{mu}\right]} \\
\text { Effective }\end{array}$ & 45 & 30 & 30 & 60 & 60 & 75 & 300 \\
\hline $\begin{array}{c}\text { Rainfall } \\
\text { [mm] }\end{array}$ & 21.2 & 25.6 & 8.5 & 39.1 & 46 & 13.6 & 154 \\
\hline $\begin{array}{c}\text { Irrigation } \\
\text { Quota } \\
{\left[\mathrm{m}^{3} / \mathrm{mu}\right]}\end{array}$ & 31 & 13 & 24 & 34 & 29 & 66 & 197 \\
\hline
\end{tabular}

\section{Conclusions}

Wohushan basin is a low mountain and hills area and is an important water source for Ji'nan city. Optimization of agricultural water in the area is of positive significance to the sustainable development of regional economy. In this paper, a long series of precipitation in the region is analyzed, and the annual precipitation and daily effective rainfall in typical level year are obtained. Considering the randomness and discontinuity factors of rainfall in water balance equation, irrigation quantity is designed referring to water requirement for growth. The result is that the current irrigation quota is reduced from $288 \mathrm{~m}^{3} / \mathrm{mu}$ to $248 \mathrm{~m}^{3} / \mathrm{mu}$, which is reduced by $11 \%$, which saves the resource of water. And then it is of great significance to realize the maximum benefit of regional water resources.

\section{Acknowledgements}

This paper is supported by Shandong nature science fund (ZR2012DL08) and Shandong major water resources science research and technology promotion project (SDSLKY201314, SDSLKY201410).

\section{References}

[1] S. Shang and X. Mao: Agricultural Water Management Vol.85(2006), p.314.

[2] Y. Huang, Y. P. Li and X. Chen: Agricultural Water Management Vol.107(2012), p.74.

[3] X.Y. Zhang and W. Qin and S.Y. Chen: Agricultural Water Management,Vol.179(2017), p.47. 
[4] W. Liu. Tian Shan irrigation optimal allocation of water resources research (MS., Shandong University, China 2013) (in Chinese).

[5] J. Huang. Study on irrigation quota of main crops in Shandong province (MS., Shandong Agricultural University, China 2011) (in Chinese). 